\title{
LEISURE ACTIVITIES FOR THE DEVELOPMENT OF CREATIVE INTELLIGENCE IN MATHEMATICAL PROBLEM SOLVING
}

\author{
Angélica Mercedes Tumbaco Castro ${ }^{1}$ (D) , Galo Ernestro Cabanilla Guerra ${ }^{2}$ (D), \\ Christian Antonio Pavón Brito ${ }^{1}$ (D) Tannia Gabriela Acosta Chávez ${ }^{1,3}$ [D
}

${ }^{1}$ Universidad de Guayaquil, Facultad de Filosofía, Letras y Ciencias de la Educación (Ecuador)
${ }^{2}$ Universidad Tecnológica Empresarial de Guayaquil (Ecuador)
${ }^{3}$ Universidad Agraria del Ecuador, Facultad de Economía Agrícola (Ecuador)
atumbaco33@gmail.com,gcabanilla@uteg.edu.ec, christian.pavonb@ug.edu.ec, tannia.acostach@ug.edu.ec

Received February 2018

Accepted March 2018

\section{Abstract}

The present work studies the influence of leisure activities on the creative intelligence of the students. An experimental pre- and post-test design was carried out with individuals selected in a sampling process. The design identifies the ease of students to place themselves in possible contexts and solve them mathematically through Polya's phases. Two target groups were then located, one of which was applied the independent variable. The results were verified using the variable contrast statistical method, which concluded that leisure activities affect creative intelligence in positive terms, since the experimental group of post-test presented greater success in the entelechy of possible scenarios, facilitating the solving of mathematical problems related to different topics.

Keywords - Mathematics, Leisure Activities, Creative Intelligence.

\section{Introduction}

This study emerges from the experience and expertise of certain teachers in the ninth year of General Basic Education, who in an attempt to make their instruction more effective, decided to experiment with the motivational aspect. They therefore first analyzed the learning difficulties associated with certain topics and then contextualized the problem in order to position it within the corresponding theoretical framework. Certain hypotheses emerged that could be linked to success in learning Mathematics.

One of the first steps taken by the research group was to identify the variables, and based on exhaustive research, imagination was identified as an element from the realm of creative intelligence, which is of great use in solving practical problems of different natures, obviously including Mathematics.

As a result of all of this, this research work is presented in order to motivate students to study mathematics and to promote leisure activities in this science. This assists both students and instructors, as it permits creative intelligence to be developed on the part of the student and allows instructors to motivate, display knowledge, and promote the stimulus of macroskills in Mathematics, such as reasoning, demonstration, representation, communication and connections. This research is also considered to be important, as it is conducted according to the output profile of General Basic Education.

For this reason, the present work seeks to establish the relationship between the use of leisure activities and creative intelligence in the Mathematics teaching-learning process. 


\subsection{Anthropological theory of the didactics}

With regard to the anthropological theory of the Didactics of Mathematics developed by Chevallard (1992) and Godino (2010) states that:

The starting point is to consider the mathematical activity and the activity involved in the study of mathematics within the set of human activities and those of the social institutions. At the start of anthropological theory, the technical notions of objects, subjects, institutions and personal and institutional relations with the objects are introduced. It is believed that these objects exist because there is "activity," in other words, human work, from which all objects emerge (Godino, 2010: page 37).

ATD proposes moments of study that are considered essential in the process of studying a mathematical organization, which are: the moment of first contact, the exploratory moment, the technical work moment, the technological-theoretical moment, the institutionalization moment and the evaluation moment.

Our research is based on the first two moments of study developed by Chevallard. The first moment is the start at which the student makes contact with the subject of study in question, seeing the need to tackle a mathematical organization; it can also be a moment of revisiting objects that he/she has previously dealt with and that reappear in a different task. The second moment is that of exploration, where a technique is sought to solve a mathematical task that is presented for the first time; it is necessary to find a way to do it, i.e., explore the technique.

\subsection{Creative intelligence}

On the other hand, creativity is subjective, given that in one way or another it has an influence on the values and virtues of each person, as long as it is guided in a positive manner at the time when it is taught.

This is confirmed in a certain manner when Gastelú (2011) states that Alan J. Rowe (2004), in his book Creative Intelligence, proposes that:

Creative Intelligence is a combination of subjective elements that range from a combination of character, a way of perceiving reality, a manner of processing information, the personal values of the individual, reaction in different situations, what we do and how we achieve it, etc. (Gastelú, 2011: page 3).

\subsection{Leisure activities}

Thus, considering our independent variable, Gómez, Molano and Rodríguez (2015) state that "leisure activities promote psycho-social development and formation of the personality, evidence values, can be oriented towards the acquisition of learning, encompassing a wide range of activities in which pleasure, enjoyment, creativity and knowledge interact" (Gómez et al., 2015: page 29).

The above shows the influence of leisure activities on the development of student creativity in education at all levels, including the university level. The approach to and solving of problems are crucial points in mathematics education, and they are also important parts of the comprehensive education of students, since they encourage the development of structures of creative, flexible and developmental intelligence.

Following all these reviews, we conclude by stating that this research hopes to promote leisure activities so that students develop creative intelligence, in the interests of facilitating mathematical problem solving, as the result of the development of part of creative intelligence that is imagination. It is also hoped to motivate learning starting with experimentation in the first encounter with the subject of study. All of this should lead to the acquisition of significant learning, since the students will have the opportunity to reveal their thoughts, ideas and concerns, producing in them the capacity to reflect, think and solve the problems of the society in which they are immersed. 


\section{Methodology}

The study was conducted in a mid-level educational institution in the city of Guayaquil. The population studied corresponds to ninth grade students of General Basic Education. The pertinent mathematical calculations were performed and the corresponding studies and analyses were applied.

The research group for the completion of the project applied sampling methods to the population. A sample of the population was chosen, which was involved in mathematical leisure activities.

A pre-test and post-test experimental design was used, which was applied to the calculated sample of students in order to establish how the leisure activities influenced their creative intelligence.

The tests used in the experimental design match the problem-solving stages by Polya, which made it possible to qualitatively measure the phases that must be completed to achieve the successful resolution of mathematical problems, so that the information collected in the tests is highly reliable and valid for measuring the different levels of mathematical competence of the participants. A more quantitative study is presented on the post-test than on the pre-test, because here we will attempt to determine the number of individuals for which representative differences were found in comparison with the pre-test with respect to the leisure activities and the students' thought.

Polya's problem-solving phases are divided into first, understanding the problem; second, coming up with a plan; third, executing the plan; and fourth, examining the solution. A Likert scale measuring quality was used in the test design, with each of Polya's phases, which ensures an entirely objective test.

The data were statistically tabulated, using the appropriate tables and graphs. Following this, the data were analyzed and the results interpreted to test the variables, using the Chi square statistics. The intent was to determine the influence of leisure activities on creative intelligence.

It should be mentioned that the success of a class was specified as knowing how to ask and causing the students to become interested in wanting to investigate more and remain active during the session. The praxis and use of methodological techniques facilitate the instructor's work because they optimize time and produce excellent results.

The paradigm that will guide the research has critical propositive nuances and is based on the general project objective, with the methodological and didactic conditions of experimental, correlational, quantitative and field research, based on realities found in classrooms.

The criterion to identify the scientific character of a theory has to do with the hypothetical deductive method, which is characterized by the testing of theories against reality. The theories are constructed as conjectures or speculative and provisional suppositions that the intellect creates in an attempt to solve problems and provide an appropriate explanation for the behavior of certain aspects of the world. These must then be rigorously tested through observation or experimentation. The theories that do not pass the test must be eliminated and replaced with others.

The formulation of hypotheses was an essential component to steer towards possible causes and consequences of not using leisure activities. Corbetta (2010) states that "the hypothetical-deductive method owes its name to the fact that two of its fundamental stages are the formulation of the hypothesis and deduction of consequences that must be tested with experience" (Corbetta, 2010: page 6).

It is particularly important to give value to (and remember it) the techniques and instruments that are used in a research study. To accomplish this, we must adequately select them, which will enable us to collect information from a set of detected phenomena, as well as tabulate and record data to facilitate the analysis of the problem and provide the respective solution. 


\section{Results}

\subsection{Population and sample}

We begin by carrying out the experimental portion with the calculation of the sample based on a certain population. The population was chosen due to the experience of the teachers at the educational level in question, which enabled them to anticipate the common learning difficulties for all the target groups; this was achieved based in the initial contextualization. The table resulting from the statistical calculation of the same, with a sample error limit of $5 \%$, is shown below:

\begin{tabular}{|c|c|c|}
\hline Stratum & Population & Sample \\
\hline Students & 157 & 113 \\
\hline
\end{tabular}

Table 1. Distribution of the Population and Sample

\subsection{Pre- and post-test experimental design}

The pre-test, also referred to as the pilot or preliminary trial, refers to the experimentation phase, while the post-test, based on the results of the pre-test, will enable us to see whether the leisure activities have an influence on the creative intelligence of the students.

After the calculation of the sample, the pre- and post-test experimental design was executed, dividing the sample into the two target groups. The first group was evaluated by means of a pre-test based on Polya's problem-solving phases for a specific curriculum block; however, the curriculum block was addressed without the use of leisure activities.

The second group was evaluated according to the same terms, but the curriculum block was approached with the use of constructivist leisure activities. It should be stressed that the leisure activities were closely related to the curriculum block being studied. The results are summarized in the following table:

\begin{tabular}{|l|r|r|r|r|r|r|}
\hline & \multicolumn{1}{|c|}{ EL } & \multicolumn{1}{|c|}{ BA } & \multicolumn{1}{c|}{ A } & AA & E & \multicolumn{1}{c|}{ Total } \\
\hline $\begin{array}{l}\text { Pre-Test } \\
\text { No leisure activities }\end{array}$ & 12 & 18 & 14 & 6 & 5 & $\mathbf{5 5}$ \\
\hline $\begin{array}{l}\text { Post-Test } \\
\text { With leisure activities }\end{array}$ & 4 & 7 & 15 & 14 & 18 & $\mathbf{5 8}$ \\
\hline Total & $\mathbf{1 6}$ & $\mathbf{2 5}$ & $\mathbf{2 9}$ & $\mathbf{2 0}$ & $\mathbf{2 3}$ & $\mathbf{1 1 3}$ \\
\hline
\end{tabular}

Table 2. Contrast of Pre- and Post-Test Frequencies

The assessment scales correspond to a variation of a Likert scale referred to as a quality scale, which is described as follows:

EL: Extremely low

BA: Below average

A: Average

\section{AA: Above average}

E: Excellent

The statistical graph summarizing the results and facilitating their observation is shown below: 


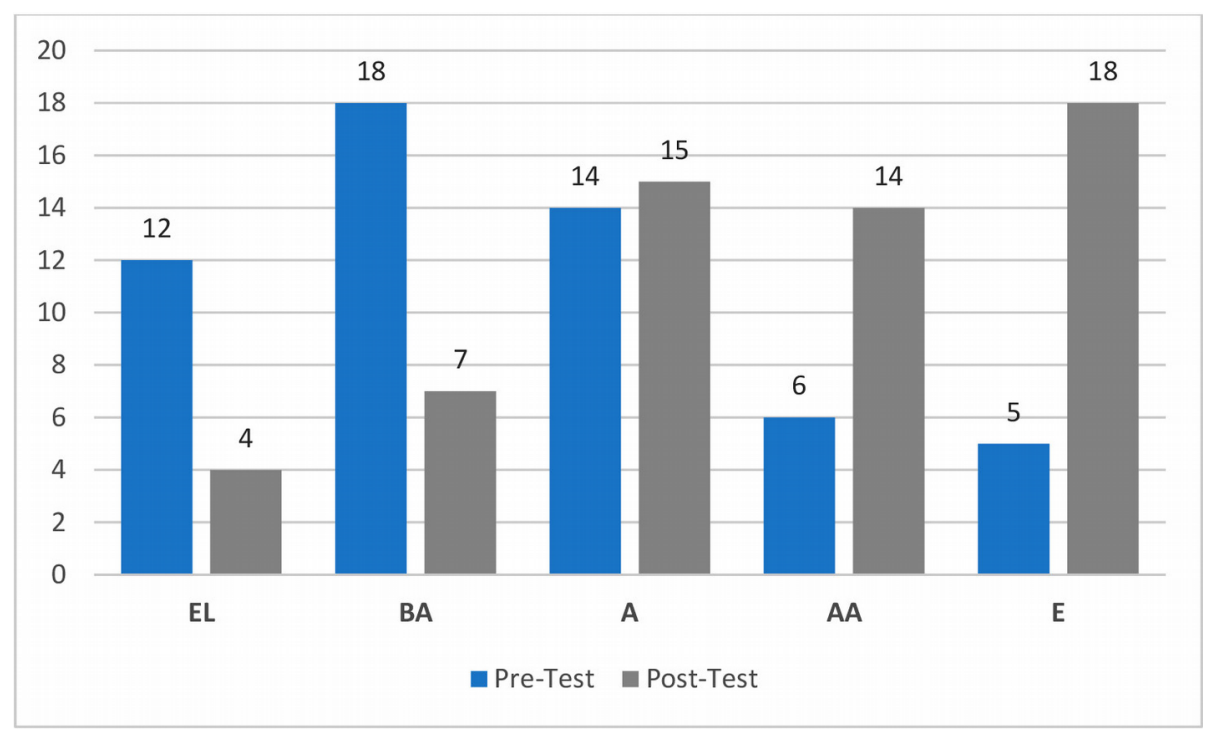

Figure 1. Statistical Graph Testing the Pre- and Post-Test Frequencies Obtained (EL: Extremely low; BA: Below average; A: Average; AA: Above average; E: Excellent)

\subsection{Variable Testing}

The statistical method used to test the variables and verify the hypothesis was the Chi square method defined as:

$$
x^{2}=\sum \frac{(f-f t)^{2}}{f t}
$$

Once applied to the data obtained, the result was:

$$
x^{2}=19.32
$$

On the other hand, we have:

$$
x^{2} \text { rom the table }=9.49
$$

We define our hypotheses:

- Null hypothesis, $H_{0}$ : The leisure activities have no influence on creative intelligence.

- Alternative hypothesis, $H_{1}$ : The leisure activities have an influence on creative intelligence.

According to the rules of this variable testing, we obtain:

- Calculated $x^{2}>x^{2}$ from the table: $H_{0}$ is rejected.

- Calculated $x^{2}<x^{2}$ from the table: $H_{1}$ is rejected.

Since $x^{2}=19.32>x^{2}=9.49: H_{0}$ is rejected and $H_{1}$ is accepted, by virtue of which, the leisure activities do have an influence on creative intelligence.

\section{Conclusions}

Imagination is part of creative intelligence and allows students to imagine possible and problematic scenarios that could be solved mathematically. 
Problems must be used to verify the curricular progress made by means of evaluation, since exercises only measure mechanized skills.

Polya's phases made it possible to qualitatively measure each of the stages through which the student must pass in order to solve practical problems.

Individuals motivated by leisure activities presented better imaginary delineation of the proposed mathematical problem.

After performing the leisure activities, the students were motivated, in anticipation of what would be considered in class. They were also observed to be more participative and alert.

Leisure activities were seen to stimulate the development of creative intelligence, and it has been observed that this is better developed when the leisure activities are closely related to the curriculum block being studied.

The progress made in the problem-solving phases improved by around thirty percent, which is fairly satisfactory, given the early stages of experimentation.

\section{Declaration of Conflicting Interests}

The authors declared no potential conflicts of interest with respect to the research, authorship, and/or publication of this article.

\section{Funding}

The authors received no financial support for the research, authorship, and/or publication of this article.

\section{References}

Chevallard, Y. (1992). Concepts fondamentaux de la didactique: Perspectives apportées par une approache anthropologique. Recherches en Didactique des Mathématiques, 12(1), 73-112.

Corbetta, P. (2010). Metodologia y técnicas de investigación social. Madrid: McGrawHill.

Gastelú, A. (2011). La inteligencia creativa. Honolulu: Atlantic International University.

Godino, J.D. (2010). Marcos teóricos sobre el conocimiento y el aprendizaje matemático. Departamento de Didáctica de la Matemática. Granada: Universidad de Granada.

Gómez, T., Molano, P., \& Rodríguez, S. (2015). La Actividad Lúdica como estrategia pedagógica para fortalecer el aprendizaje de los niños. Ibagué: Universidad de Tolima.

Rowe, A. (2004). Creative intelligence: discovering the innovative potential in ourselves and others. Upper Saddle River, N.J: Pearson/Prentice Hall.

Published by OmniaScience (www.omniascience.com)

Journal of Technology and Science Education, 2018 (www.jotse.org)

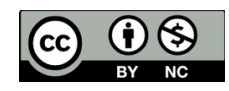

Article's contents are provided on an Attribution-Non Commercial 4.0 Creative commons International License.

Readers are allowed to copy, distribute and communicate article's contents, provided the author's and JOTSE journal's names are included. It must not be used for commercial purposes. To see the complete licence contents, please visit https://creativecommons.org/licenses/by-nc/4.0/. 